\title{
Clinical observation of apatinib-related hypothyroidism in patients with advanced malignancies
}

\author{
JUNJUAN XIAO $^{1}$, JING LIANG $^{1}$, WEI ZHANG ${ }^{2}$ and YAN LI ${ }^{1}$ \\ Departments of ${ }^{1}$ Oncology and ${ }^{2}$ Ultrasonography, Shandong Provincial Qianfoshan Hospital, \\ Shandong University, Jinan, Shandong 250014, P.R. China
}

Received August 12, 2019; Accepted April 7, 2020

DOI: $10.3892 /$ etm.2020.8937

\begin{abstract}
Thyroid dysfunction has been previously reported during treatment with certain small-molecule multi-tyrosine kinase inhibitors, including sunitinib and sorafenib. Apatinib, which has a similar mechanism of action to these inhibitors, has reportedly induced hypothyroidism during treatment. Fully elucidating drug-associated adverse events could aid in patient monitoring and recommendations of suitable management strategies. The current 2-year observational study monitored patients with solid tumors who were prescribed apatinib. A total of 149 patients treated with apatinib from February 2015 to January 2016 were included. Their thyroid function and thyroid ultrastructure was evaluated for at least 24 months or until death. The primary objective of the current study was evaluating accepted thyroid replacement treatment. Secondary objective was ultrastructural changes in the thyroid gland. The current study was approved by the Medical Ethics Committee of Qianfoshan Hospital, affiliated with Shandong University and written informed consent was obtained from all patients prior to commencing the clinical trial. A total of $53(35.57 \%)$ patients developed hypothyroidism, which varied from subclinical (12 cases; $8.05 \%$ ) to clinical (41 cases; $27.52 \%)$. Thyroid nodules were noted in 15 cases $(10.07 \%)$. Furthermore, 3 cases $(2.01 \%)$ had thyroid imaging reporting and data system scores of $4 \mathrm{a} / 4 \mathrm{~b} / 4 \mathrm{c}$ and 12 cases $(8.05 \%)$ had scores of 1,2 and 3. A total of 25 patients (16.78\%) experienced 1-2 grade fatigue and 2 patients (1.34\%) reported $3-4$ grade fatigue. There was no reported association between disease control rate and hypothyroidism. Apatinib significantly increased the risk of clinically relevant hypothyroidism and altered thyroid gland structure.
\end{abstract}

Correspondence to: Professor Yan Li, Department of Oncology, Shandong Provincial Qianfoshan Hospital, Shandong University, 16766 Jingshi Road, Jinan, Shandong 250014, P.R. China

E-mail: liyan16766@163.com

Key words: hypothyroidism, apatinib, adverse reaction

\section{Introduction}

Apatinib, a small-molecule tyrosine kinase inhibitor (TKI), selectively binds to and inhibits vascular endothelial growth factor receptor-2 (VEGFR-2) (1). This consequently inhibits VEGF-stimulated endothelial cell migration and proliferation, and decreases microvascular tumor density (1). Certain pre-clinical and clinical data have utilized apatinib in the treatment of solid tumors, which has led to the approval of the drug as a second-line treatment for patients with advanced gastric tumors in China in 2014 (2).

Additionally, apatinib has undergone Phase II/III clinical trials for non-small-cell lung cancer, esophageal cancer, hepatocellular carcinoma and breast cancer in China (3-7)

The most common side effects of apatinib are hypertension, gastrointestinal distress, skin toxicity, fatigue and elevated transaminases (8). However, to the best of our knowledge, no studies have examined hypothyroidism induced by apatinib. Hypothyroidism can lead to severe consequences if left untreated, including fatigue, intolerance to cold, acroparesthesia, dryness of the skin and hair, weight gain, constipation, hoarseness of the voice, typical facial appearance and prolonged relaxation phase of the tendon reflexes (9). Therefore, appropriate monitoring and treatment recommendations in patients receiving apatinib are critical.

The primary objective of the current study was to assess the number of patients who accepted thyroid replacement therapy after commencing treatment with apatinib. The secondary objective was to investigate thyroid ultrastructure remodeling. To summarize, the current study evaluated the incidence and severity of clinically actionable hypothyroidism induced by apatinib.

\section{Materials and methods}

Patient selection and therapy. A total of 149 patients with pathologically diagnosed solid tumors who were treated with apatinib from February 2015 to January 2016 in Shandong Provincial Qianfoshan Hospital were recruited for the current study. All cases were diagnosed as stage IIIC or IV and had no standard alternative curative therapy. Additional eligibility criteria included: Age between 18 and 70 years, no history of other cancers, an Eastern Cooperative Oncology Group performance status (10) between 0-3 and a life expectancy 
of $>3$ months. Exclusion criteria was the presence of thyroid disease, other than thyroid cancer.

At baseline, all patients underwent a computed tomography scan or magnetic resonance imaging, a thyroid ultrasound and blood tests. All study subjects had normal hematological, thyroid, hepatic, renal and cardiac functions prior to treatment (counts of leukocytes, erythrocytes and thrombocytes; levels of triiodothyronine, tetraiodothyronine, thyroid stimulating hormone, lactic dehydrogenase and brain natriuretic peptide; and rates of alanine transaminase, aspartate aminotransferase and creatinine clearance were assessed). All these parameters were normal in each patient.

Evaluation and method. All patients received $500 \mathrm{mg}$ apatinib/day (Jiangsu Heng Rui Medicine Co., Ltd.) orally until the disease progressed, except for 3 patients who were administered a dose of $250 \mathrm{mg}$ /day due to hypertension. Dose reductions occurred often due to toxicity, as such the doses of 11 patients were reduced to $250 \mathrm{mg}$ /day.

Levels of triiodothyronine (T3; normal range, 3.1-6.8 pmol/1), tetraiodothyronine (T4; normal range, $12-22 \mathrm{pmol} / \mathrm{l}$ ) and thyroid stimulating hormone (TSH; 0.27-4.2 $\mu \mathrm{IU} / \mathrm{ml}$ ) were evaluated monthly. These parameters were evaluated using Elecsys FT3 III, FT4 III and TSH and Cobase E analyzers supplied by Roche Diagnostics GmbH. Lower levels of T3 and T4 were $<3.1$ and $12 \mathrm{pmol} / 1$, respectively. Higher levels of TSH were $>4.2 \mu \mathrm{IU} / \mathrm{ml}$.

Additionally, patients underwent a thyroid ultrasound every 2 months while receiving apatinib treatment. Their thyroid function and thyroid ultrastructure was evaluated for at least 24 months or until death. All patients divided into the normal thyroid function group (96 cases) and the hypothyroidism group (53 cases) according to their levels of T3, T4 and TSH. Efficacy measures included complete response(CR), partial response (PR), stable disease (SD) and disease control rate (DCR; including complete response, partial response and stable disease). Statistical differences in DCR between the two groups were analyzed.

Statistical analysis. Statistical analysis of the data was performed using SPSS (version 18.0; SPSS, Inc.). All quantitative data are presented as mean \pm SD of three independent repeats. Pearson $\chi^{2}$ test was used for the comparison of parameters. $\mathrm{P}<0.05$ was considered to indicate a statistically significant difference. The current study was granted access to information that could identify individual participants during data collection through the health information system at Shandong Provincial Qianfoshan Hospital.

\section{Results}

Demographics. The demographic characteristics of 149 patients with solid tumors are presented in Table I: Apatinib was administered to patients with gastric, hepatic, colorectal, pancreatic, lung, breast, ovarian and kidney cancer, as well as soft tissue sarcoma. A total of 21 cases were diagnosed at stage IIIc and 128 cases at stage IV.

Toxicity and tolerability. The most frequently observed drug-related adverse events (AEs) were hypertension, hand-foot syndrome, hypothyroidism, elevated transaminases,
Table I. Demographic characteristics of 149 patients with solid tumors.

\begin{tabular}{|c|c|}
\hline Characteristic & Number of cases $(\%)$ \\
\hline \multicolumn{2}{|l|}{ Age (years) } \\
\hline$<65$ & $99(66.44)$ \\
\hline$\geq 65$ & $50(33.56)$ \\
\hline \multicolumn{2}{|l|}{ Sex } \\
\hline Male & $64(42.95)$ \\
\hline Female & $85(57.05)$ \\
\hline \multicolumn{2}{|l|}{ Primary tumor site } \\
\hline Gastric & $54(36.24)$ \\
\hline Hepatic & $13(8.72)$ \\
\hline Colorectal & $12(8.05)$ \\
\hline Pancreatic & $3(2.01)$ \\
\hline Lung & $17(11.41)$ \\
\hline Breast & $16(10.74)$ \\
\hline Ovarian & $18(12.08)$ \\
\hline Kidney & $13(8.72)$ \\
\hline Soft tissue sarcoma & $3(2.01)$ \\
\hline \multicolumn{2}{|l|}{ Stage } \\
\hline IIIc & $21(14.09)$ \\
\hline IV & $128(85.91)$ \\
\hline \multicolumn{2}{|l|}{ ECOG performance status } \\
\hline $0-1$ & $12(8.05)$ \\
\hline 2 & $71(47.65)$ \\
\hline 3 & $66(44.30)$ \\
\hline \multicolumn{2}{|l|}{ Prior therapy } \\
\hline Chemotherapy & 76 \\
\hline Radiotherapy & 32 \\
\hline Surgery & 97 \\
\hline Tyrosine kinase inhibitors & 32 \\
\hline Total & 149 \\
\hline
\end{tabular}

ECOG, Eastern Cooperative Oncology Group.

diarrhea, albinism, rash, anorexia, mucosal ulcers, fatigue and proteinuria. In the current study, only drug-related hypothyroidism AEs, including hypothyroidism, ultrastructural changes and fatigue are discussed. A total of $53(35.57 \%)$ patients had hypothyroidism (Table II), which varied from alterations in THS with normal T3 and T4 (12 cases; $8.05 \%$ ) to higher TSH with lower T3 and T4 (41 cases; 27.52\%). Thyroid nodules were found in 15 cases $(10.07 \%)$. A total of 3 cases $(2.01 \%)$ had thyroid imaging reporting and data system for ultrasonography scores (11) of $4 \mathrm{a} / 4 \mathrm{~b} / 4 \mathrm{c}$ and 12 cases $(8.05 \%)$ had scores of 1,2 and 3 . Another drug-related AE was fatigue $(16.78 \% ; 25$ cases of grade $1-2$; and $1.34 \%$; 2 cases of grade 3-4).

The incidence of hypothyroidism increased gradually as apatinib treatment duration increased $(28.1 \%$ at 12 months and $34.6 \%$ at 24 months; Fig. 1). Additionally, 2 cases of ultrastructural changes in the thyroid gland were reported. 
Table II. Summary of adverse events in 53 patients with hypothyroidism.

\begin{tabular}{lc}
\hline Adverse event & Number of cases $(\%)$ \\
\hline Hypothyroidism & $53(35.57)$ \\
Normal T3, T4 and higher TSH & $12(8.05)$ \\
Lower T3, T4 and higher TSH & $41(27.50)$ \\
Ultrastructural changes & $15(10.07)$ \\
Ti-RADs $1 / 2 / 3$ & $12(8.05)$ \\
Ti-RADs 4a/4b/4c & $3(2.01)$ \\
Fatigue & $27(18.12)$ \\
1-2 grades & $25(16.78)$ \\
$3-4$ grades & $2(1.34)$ \\
\hline
\end{tabular}

T3, triiodothyronine; T4, tetraiodothyronine; TSH, thyroid stimulating hormone; Ti-RADs, Thyroid Imaging Reporting and Data System.

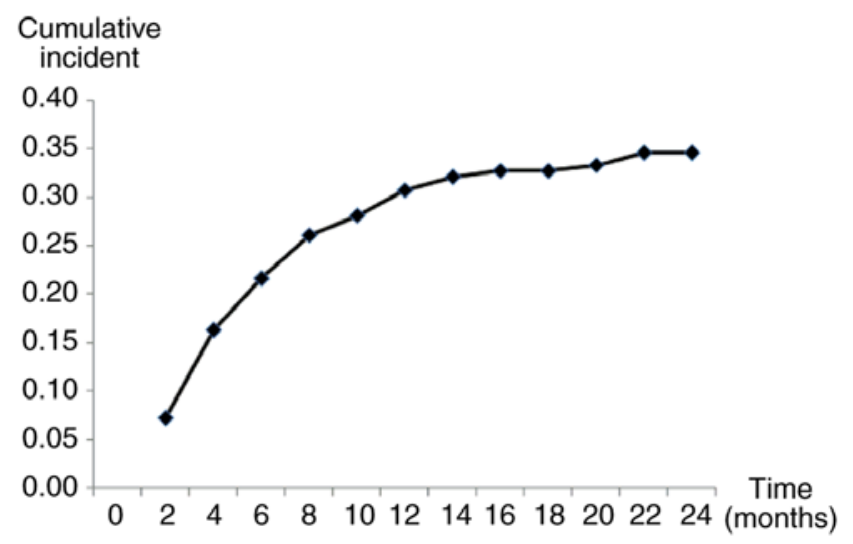

Figure 1. Incidence of hypothyroidism with apatinib treatment.

However, normal thyroid function was noted in both cases. Apatinib treatment of 1 year shrunk the thyroid gland in a patient who had a $9.0 \times 6.0 \mathrm{~mm}$ nodule in the right lobe of the thyroid gland prior to apatinib treatment. The nodule increased to $10.0 \times 8.0 \mathrm{~mm}$ after treatment (Fig. 2). Furthermore, after 9 months of apatinib treatment, thyroid ultrasound revealed two new nodules $(3.5 \times 2.0$ and $8.4 \times 4.9 \mathrm{~mm})$ in a second patient who had normal thyroid function prior to treatment (Fig. 3).

DCR and hypothyroidism. A total of 6 patients attained PR and 28 attained SD in the normal thyroid function group. In the hypothyroidism group, 2 patients attained PR and 19 attained SD. No significant difference was noted $(\mathrm{P}=0.61$; Table III).

\section{Discussion}

Since determining the role of VEGF and VEGFR in carcinogenesis $(12,13)$, therapeutic strategies against these targets have been widely studied (13-16). Oral TKIs that inhibit VEGFR (sorafenib, sunitinib, axitinib, cediranib and pazopanib) have since been elucidated and have been reported to have similar mechanisms of action and toxicities (13-16).
Table III. DCR and hypothyroidism.

\begin{tabular}{|c|c|c|c|c|}
\hline Group (no. of patients) & PR & $\mathrm{SD}$ & DCR & P-value \\
\hline Normal thyroid function (96) & 6 & 28 & 54 & 0.61 \\
\hline Hypothyroidism (53) & 2 & 19 & 39.6 & \\
\hline
\end{tabular}

DCR, disease control rate; PR partial response; $\mathrm{SD}$, stable disease.

The antitumor activity of sorafenib and sunitinib is mediated through the inhibition of VEGFRs, platelet-derived growth factor receptor and stem cell factor receptor $(17,18)$. This inhibition results in apoptotic and antiangiogenic effects. Sorafenib has been approved for treatment in advanced hepatocellular carcinoma, metastatic renal cell carcinoma and radioiodine refractory differentiated thyroid carcinoma (19-21).Furthermore, sorafenib has also been approved for treatment in advanced renal cell carcinoma, imatinib-resistant/-intolerant gastrointestinal stromal tumors and also for certain patients with progressive, well-differentiated pancreatic neuroendocrine tumors. Sorafenib and sunitinib are relatively well-tolerated $(22,23)$.

Apatinib has a binding affinity that is $10 \mathrm{x}$ higher than that of sorafenib (24). Sorafenib and sunitinib were previously demonstrated to cause hypothyroidism in $6.3-27 \%$ and $10-85 \%$ of cases, respectively (25-31). The severity of hypothyroidism is hypothesized to be associated with the dose and duration of sorafenib and sunitinib treatment (26). Certain proposed molecular mechanisms have been hypothesized for TKI-induced hypothyroidism, including inhibition of radioactive iodine uptake by the thyroid gland (32), inhibition of VEGFR and/or platelet-derived growth factor receptor (25) and via an autoimmune mechanism of thyroid gland damage, which is supported by the observation of lymphocytic thyroiditis among certain patients receiving the drug (33). Lack of treatment can decrease patients' quality of life (34).

Currently, few studies have assessed the association between apatinib and thyroid dysfunction. The current study observed apatinib-related hypothyroidism in numerous patients with solid tumors. The incidence was similar to the reported incidence of sorafenib and sunitinib-related hypothyroidism (25-31). The results of current study indicated that clinicians should monitor thyroid functions in patients that receive apatinib. Furthermore, timely supplementation of thyroxine may improve patient's tolerance and quality of life.

In conclusion, the present study reported data of the incidence of clinically actionable AEs. Appropriate management of hypothyroidism may improve the tolerability of apatinib, patient quality of life and overall survival. However, the present study had limitations. A statistical significance between the effect of apatinib and thyroid dysfunction was not established and the mechanism of apatinib-induced thyroid dysfunction was not assessed. In future reports, a cohort study concerning the presence of anti-angiogenesis-related hypothyroidism as a potential biomarker of antitumor efficacy in patients with metastatic cancer receiving apatinib should be conducted, followed by a relevant mechanism study to supplement these limitations. 


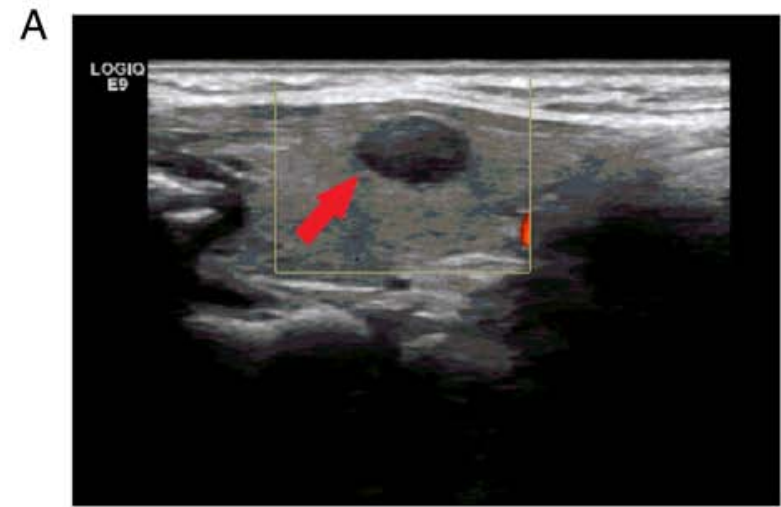

B

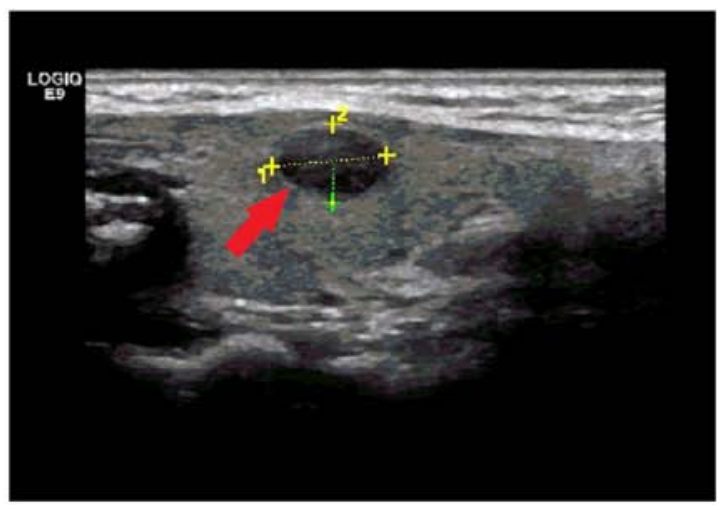

C

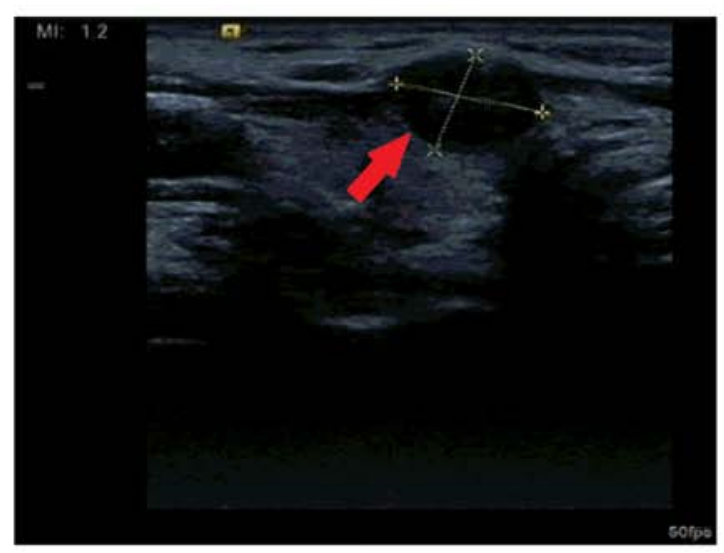

D

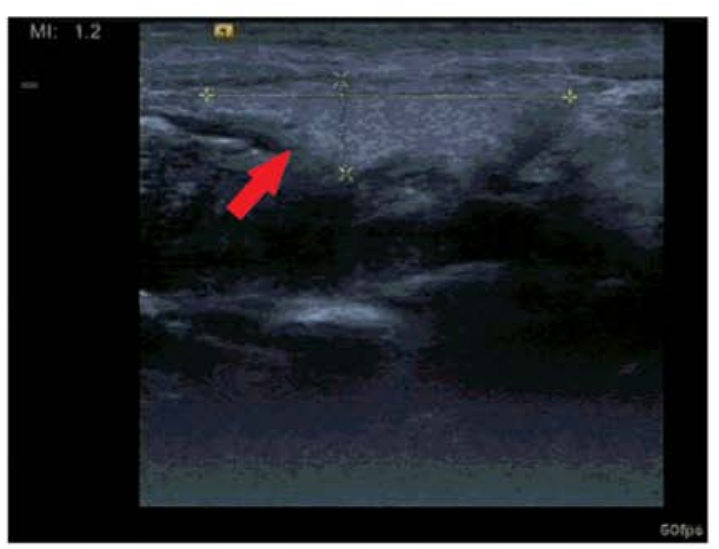

Figure 2. Ultrastructural changes in the thyroid gland. (A) Thyroid ultrasound before apatinib treatment. (B) A 9.0x6.0 mm nodule was revealed in the right lobe of the thyroid gland. (C) Thyroid ultrasound after one year of apatinib treatment. (D) Thyroid gland was reported to have shrunk and the nodule currently measures $10 \times 8 \mathrm{~mm}$.

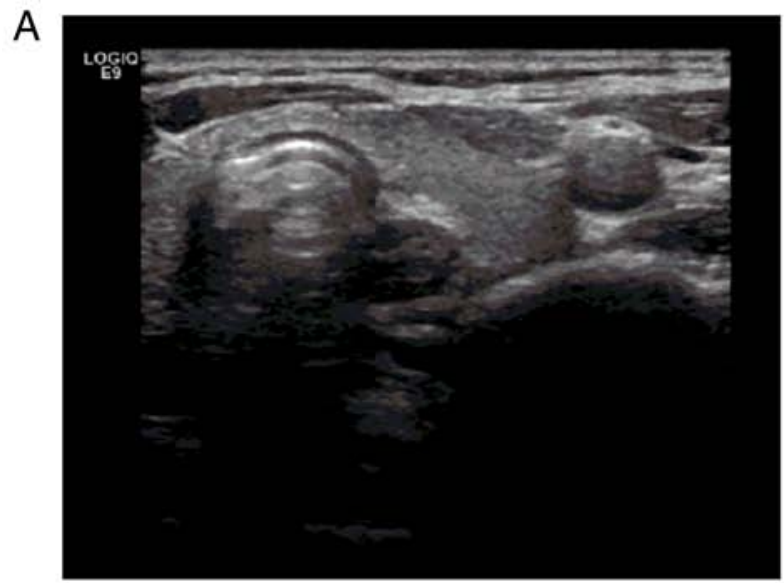

B
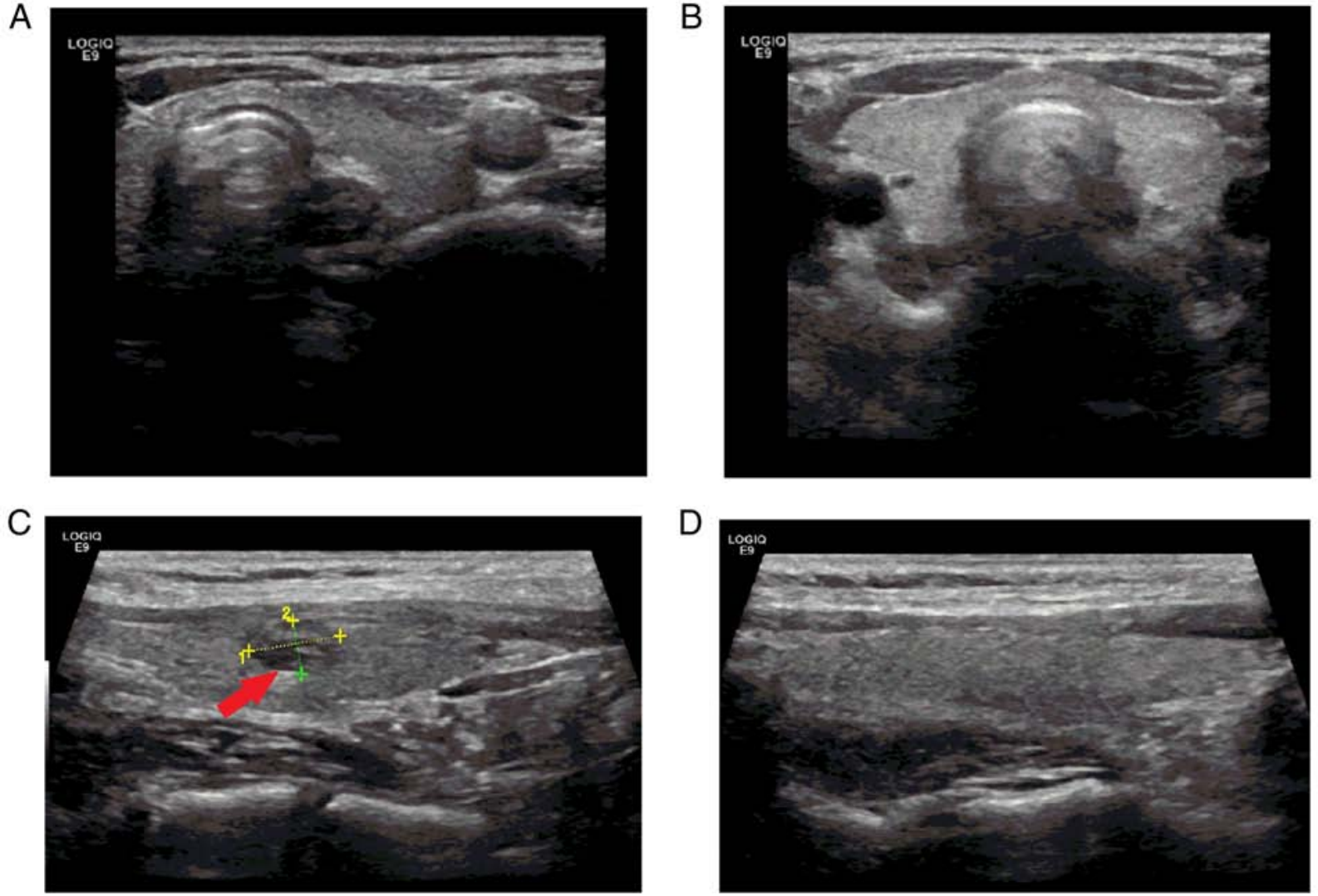

Figure 3. Ultrastructural changes in the thyroid gland. (A) Thyroid ultrasound before apatinib treatment. (B) Normal thyroid gland without structural changes. (C) Thyroid ultrasound after 9 months of apatinib treatment. (D) One new nodule was reported $(8.4 \times 4.9 \mathrm{~mm})$ after 9 months of apatinib treatment. 


\section{Acknowledgements}

Not applicable.

\section{Funding}

No funding was received.

\section{Availability of data and materials}

The datasets used and/or analyzed during the present study are available from the corresponding author on reasonable request.

\section{Authors' contributions}

JX, JL and YL analyzed and interpreted the patient data regarding hematological and imaging examinations. JX and YL wrote the manuscript. WZ performed thyroid ultrasound examinations. All authors read and approved the final manuscript.

\section{Ethics approval and consent to participate}

The current study was designed in accordance with the legal requirements and principles of the Declaration of Helsinki and was approved by the Medical Ethics Committee of Qianfoshan Hospital, affiliated to Shandong University. Written informed consent was obtained from all patients prior to commencing the clinical trial.

\section{Patient consent for publication}

Written informed consent for publication of any associated data and accompanying images were obtained from all patients or their parents, guardians or next of kin.

\section{Competing interests}

The authors declare that they have no competing interests.

\section{References}

1. Scott AJ, Messersmith WA and Jimeno A: Apatinib: A promising oral antiangiogenic agent in the treatment of multiple solid tumors. Drugs Today (Barc) 51: 223-229, 2015.

2. Li J, Qin S, Xu J, Guo W, Xiong J, Bai Y, Sun G, Yang Y, Wang L, Xu N, et al: Apatinib for chemotherapy-refractory advanced metastatic gastric cancer: Results from a randomized, placebo-controlled, parallel-arm, phase II trial. J Clin Oncol 31: 3219-3225, 2013.

3. Wu F, Zhang S, Xiong A, Gao G, Li W, Cai W, Su C, Chen X, Zhou $\mathrm{F}$, Zhao J, et al: A phase II clinical trial of apatinib in pretreated advanced non-squamous non-small-cell lung cancer. Clin Lung Cancer 19: e831-e842, 2018.

4. Li J, Qin S, Xu J, Xiong J, Wu C, Bai Y, Liu W, Tong J, Liu Y, $\mathrm{Xu} \mathrm{R}$, et al: Randomized, double-blind, placebo-controlled phase III trial of apatinib in patients with chemotherapy-refractory advanced or metastatic adenocarcinoma of the stomach or gastroesophageal junction. J Clin Oncol 34: 1448-1454, 2016.

5. Lu W, Jin XL, Yang C, Du P, Jiang FQ, Ma JP, Yang J, Xie P and Zhang Z: Comparison of efficacy between TACE combined with apatinib and TACE alone in the treatment of intermediate and advanced hepatocellular carcinoma: A single-center randomized controlled trial. Cancer Biol Ther 18: 433-438, 2017.
6. Hu X, Zhang J, Xu B, Jiang Z, Ragaz J, Tong Z, Zhang Q, Wang X, Feng J, Pang D, et al: Multicenter phase II study of apatinib, a novel VEGFR inhibitor in heavily pretreated patients with metastatic triple negative breast cancer. Int J Cancer 135: 1961-1969, 2014.

7. Hu X, Cao J, Hu W, Wu C, Pan Y, Cai L, Tong Z, Wang S, Li J, Wang Z, et al: Multicenter phase II study of apatinib in non-triple-negative metastatic breast cancer. BMC Cancer 14: 820,2014

8. Zhang Y, Han C, Li J, Zhang L, Wang L, Ye S, Hu Y and Bai L: Efficacy and safety for Apatinib treatment in advanced gastric cancer: A real world study. Sci Rep 7: 13208, 2017.

9. Evered D and Hall R: Hypothyroidism. Br Med J 1: 290-293, 1972.

10. Oken MM, Creech RH, Tormey DC, Horton J, Davis TE, McFadden ET and Carbone PP: Toxicity and response criteria of the Eastern cooperative oncology group. Am J Clin Oncol 5: 649-655, 1982.

11. Park VY, Kim EK, Kwak JY, Yoon JH, Kim MJ and Moon HJ: Thyroid imaging reporting and data system and ultrasound elastography: Diagnostic accuracy as a tool in recommending repeat fine-needle aspiration for solid thyroid nodules with non-diagnostic fine-needle aspiration cytology. Ultrasound Med Biol 42: 399-406, 2016.

12. Chatterjee S, Heukamp LC, Siobal M, Schottle J, Wieczorek C, Peifer M, Frasca D, Koker M, König K, Meder L, et al: Tumor VEGF: VEGFR2 autocrine feed-forward loop triggers angiogenesis in lung cancer. J Clin Invest 123: 1732-1740, 2013.

13. Zhang Q, Yu C, Peng S, Xu H, Wright E, Zhang X, Huo X, Cheng E, Pham TH, Asanuma K, et al: Autocrine VEGF signaling promotes proliferation of neoplastic Barrett's epithelial cells through a PLC-dependent pathway. Gastroenterology 146: 461-472 e6, 2014.

14. Oudard S, Beuselinck B, Decoene J and Albers P: Sunitinib for the treatment of metastatic renal cell carcinoma. Cancer Treat Rev 37: 178-184, 2011.

15. Abdel-Rahman O: Systemic therapy for hepatocellular carcinoma (HCC): From bench to bedside. J Egypt Natl Canc Inst 25: 165-171, 2013.

16. Lin ZZ, Chen BB, Hung YP, Huang PH, Shen YC, Shao YY, Hsu CH, Cheng AL, Lee RC, Chao Y and Hsu C: A multicenter phase II study of second-line axitinib for patients with advanced hepatocellular carcinoma failing first-line sorafenib monotherapy. Oncologist 2020 (Epub ahead of print).

17. Clark JW, Eder JP, Ryan D, Lathia C and Lenz HJ: Safety and pharmacokinetics of the dual action Raf kinase and vascular endothelial growth factor receptor inhibitor, BAY 43-9006, in patients with advanced, refractory solid tumors. Clin Cancer Res 11: 5472-5480, 2005.

18. Mendel DB, Laird AD, Xin X, Louie SG, Christensen JG, Li G, Schreck RE, Abrams TJ, Ngai TJ, Lee LB, et al: In vivo antitumor activity of SU11248, a novel tyrosine kinase inhibitor targeting vascular endothelial growth factor and platelet-derived growth factor receptors: Determination of a pharmacokinetic/pharmacodynamic relationship. Clin Cancer Res 9: 327-337, 2003.

19. Rovesti G, Orsi G, Faloppi L, Gramantieri L, Silvestris N, Marisi G, Foschi F, Tamburini E, Andrikou K, Molinaro E ,et al: Sorafenib in patients with hepatocellular carcinoma: 10 years of real life. Ann Oncol 30 (Suppl 4): S57, 2019.

20. Flaherty KT, Manola JB, Pins M, McDermott DF, Atkins MB, Dutcher JJ, George DJ, Margolin KA and DiPaola RS: BEST: A randomized phase II study of vascular endothelial growth factor, RAF kinase, and mammalian target of rapamycin combination targeted therapy with bevacizumab, sorafenib, and temsirolimus in advanced renal cell carcinoma-a trial of the ECOG-ACRIN cancer research group (E2804). J Clin Oncol 33: 2384-2391, 2015.

21. Worden F, Fassnacht M, Shi Y, Hadjieva T, Bonichon F, Gao M, Fugazzola L, Ando Y, Hasegawa Y, Park DJ, et al: Safety and tolerability of sorafenib in patients with radioiodine-refractory thyroid cancer. Endocr Relat Cancer 22: 877-887, 2015.

22. Thorn CF, Sharma MR, Altman RB and Klein TE: PharmGKB summary: Pazopanib pathway, pharmacokinetics. Pharmacogenet Genomics 27: 307-312, 2017.

23. Doherty KR, Wappel RL, Talbert DR, Trusk PB, Moran DM, Kramer JW, Brown AM, Shell SA and Bacus S: Multi-parameter in vitro toxicity testing of crizotinib, sunitinib, erlotinib, and nilotinib in human cardiomyocytes. Toxicol Appl Pharmacol 272: 245-255, 2013.

24. Tian S, Quan H, Xie C, Guo H, Lue F, Xu Y, Li J and Lou L: YN968D1 is a novel and selective inhibitor of vascular endothelial growth factor receptor-2 tyrosine kinase with potent activity in vitro and in vivo. Cancer Sci 102: 1374-1380, 2011. 
25. Mannavola D, Coco P, Vannucchi G, Bertuelli R, Carletto M, Casali PG, Beck-Peccoz P and Fugazzola L: A novel tyrosine-kinase selective inhibitor, sunitinib, induces transient hypothyroidism by blocking iodine uptake. J Clin Endocrinol Metab 92: 3531-3534, 2007.

26. Rini BI, Tamaskar I, Shaheen P, Salas R, Garcia J, Wood L, Reddy S, Dreicer R and Bukowski RM: Hypothyroidism in patients with metastatic renal cell carcinoma treated with sunitinib. J Natl Cancer Inst 99: 81-83, 2007.

27. Wong E, Rosen LS, Mulay M, VanVugt A, Dinolfo M, Tomoda C, Sugawara M and Hershman JM: Sunitinib induces hypothyroidism in advanced cancer patients and may inhibit thyroid peroxidase activity. Thyroid 17: 351-355, 2007.

28. Tamaskar I, Bukowski R, Elson P, Ioachimescu AG, Wood L, Dreicer R, Mekhail T, Garcia J and Rini BI: Thyroid function test abnormalities in patients with metastatic renal cell carcinoma treated with sorafenib. Ann Oncol 19: 265-268, 2008.

29. Wolter P, Stefan C, Decallonne B, Dumez H, Bex M, Carmeliet P and Schöffski P: The clinical implications of sunitinib-induced hypothyroidism: A prospective evaluation. Br J Cancer 99: 448-454, 2008.

30. Clemons J, Gao D, Naam M, Breaker K, Garfield D and Flaig TW: Thyroid dysfunction in patients treated with sunitinib or sorafenib. Clin Genitourin Cancer 10: 225-231, 2012.
31. Feldt S, Schussel K, Quinzler R, Franzmann A, Czeche S, Ludwig WD and Schulz M: Incidence of thyroid hormone therapy in patients treated with sunitinib or sorafenib: A cohort study. Eur J Cancer 48: 974-981, 2012.

32. Baffert F, Le T, Sennino B, Thurston G, Kuo CJ, Hu-Lowe D and McDonald DM: Cellular changes in normal blood capillaries undergoing regression after inhibition of VEGF signaling. Am J Physiol Heart Circ Physiol 290: H547-H559, 2006.

33. Alexandrescu DT, Popoveniuc G, Farzanmehr H, Dasanu CA, Dawson N and Wartofsky L: Sunitinib-associated lymphocytic thyroiditis without circulating antithyroid antibodies. Thyroid 18: 809-812, 2008

34. Walko CM, Aubert RE, La-Beck NM, Clore G, Herrera V, Kourlas H, Epstein RS and McLeod HL: Pharmacoepidemiology of clinically relevant hypothyroidism and hypertension from sunitinib and sorafenib. Oncologist 22: 208-212, 2017.

(i) (9) This work is licensed under a Creative Commons

EY NG No Attribution-NonCommercial-NoDerivatives 4.0 International (CC BY-NC-ND 4.0) License. 